\title{
Paul Bleton - Mario Poirier, Le vagabond stoïque
}

\section{Emanuele Kanceff}

\section{(2) OpenEdition}

\section{Journals}

\section{Edizione digitale}

URL: http://journals.openedition.org/studifrancesi/35136

DOI: 10.4000/studifrancesi.35136

ISSN: 2427-5856

\section{Editore}

Rosenberg \& Sellier

\section{Edizione cartacea}

Data di pubblicazione: 1 novembre 2005

Paginazione: 448

ISSN: 0039-2944

\section{Notizia bibliografica digitale}

Emanuele Kanceff, «Paul Bleton - Mario Poirier, Le vagabond stö̈que», Studi Francesi [Online], 146 (XLIX I II) | 2005, online dal 30 novembre 2015, consultato il 18 avril 2021. URL: http://

journals.openedition.org/studifrancesi/35136 ; DOI: https://doi.org/10.4000/studifrancesi.35136

\section{Questo documento è stato generato automaticamente il 18 avril 2021.}

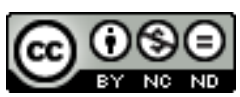

Studi Francesi è distribuita con Licenza Creative Commons Attribuzione - Non commerciale - Non opere derivate 4.0 Internazionale. 


\section{Paul Bleton - Mario Poirier, Le vagabond stoïque}

Emanuele Kanceff 


\section{NOTIZIA}

PAUL BLETON - MARIO POIRIER, Le vagabond stoïque, Louis Hémon, Montréal, Les Presses de l'Université de Montréal, 2004, 261 pp.

1 Questo poeta errabondo, questo scrittore dal tragico destino, merita certamente di essere riesumato dalla critica e che gli sia fatta giustizia terminando ormai di considerarlo autore di un solo libro. La sua morte prematura, la pubblicazione postuma e frammentaria della sua opera, hanno concorso a una certa distorsione dell'immagine che gli A. vogliono contestare ed aggiornare, facendola uscire dalla «fixation muséale» che ha assunto. Per ottenere lo scopo, essi pensano che non ci sia che una strada: «dépayser Hémon». Invece di leggere il suo celebre romanzo, Maria Chapdelaine, come un'opera nazionale o nazionalista, occorre situare lo scrittore in rapporto ai romanzi regionalisti del suo tempo. Occorre, poi, non accontentarsi di vedere in lui il romanziere ma capire quanto Hémon, prima di molti altri, si inserisca prematuramente in una cultura mediatica. Lungi dall'essere un uomo radicato nel suo territorio, Hémon deve apparirci quale fu effettivamente, un vagabondo, un itinerante, un "passeur culturel».

2 Altro compito che gli autori considerano imprescindibile e si assumono in questo libro è la scoperta del peso determinante che le relazioni familiari, cui dedicano numerosi e originali capitoli, ebbero nella vita e nell'opera dello scrittore. Studiando i membri della sua famiglia in rapporto con l'opera, gli autori fanno apparire la contraddizione centrale di uno scrittore stretto tra il desiderio di singolarità e la difficoltà di staccarsi ai legami che lo imprigionano. Una riflessione sulla condizione di sradicamento culturale («Penser le déracinement aujourd'hui») conclude l'originale studio. 